GRANGEIRO, L.C.; CECÍLIO FILHO, A.B. Exportação de nutrientes pelos frutos de melancia em função de épocas de cultivo, fontes e doses de potássio. Horticultura Brasileira, Brasília, v.22, n.4, p.740-743, out-dez 2004.

\title{
Exportação de nutrientes pelos frutos de melancia em função de épocas de cultivo, fontes e doses de potássio
}

\author{
Leilson C. Grangeiro' ${ }^{1}$; Arthur B. Cecílio Filho² \\ ${ }^{1}$ ESAM, Depto. Fitotecnia, C. Postal 137, 59625-900 Mossoró-RN; E-mail: leilson@ esam.br; ${ }^{2}$ UNESP-FCAV, Depto. Produção Vegetal, \\ Via de acesso Prof. Paulo Donato Castellane, s/n, 14884-900 Jaboticabal-SP.
}

\section{RESUMO}

Foram conduzidos dois experimentos em propriedades rurais, localizadas próxima a cidade de Borborema (SP), de outubro a dezembro/2001 e de fevereiro a abril/2002, com o objetivo de determinar as quantidades exportadas de nutrientes pelos frutos de melancia, em função de fontes e doses de potássio, em duas épocas de cultivo. O delineamento experimental utilizado foi o de blocos casualizados completos, em esquema fatorial $3 \times 4$, com três repetições, sendo avaliados as fontes: cloreto, nitrato e sulfato de potássio e as doses: 50; 100; 200 e $300 \mathrm{~kg} \mathrm{ha}^{-1}$ de $\mathrm{K}_{2} \mathrm{O}$. Com exceção do $\mathrm{Mg}$, as maiores exportações de nutrientes pelos frutos foram obtidas no cultivo de outubro a dezembro. A massa seca e as exportações de N, $\mathrm{P}, \mathrm{K}$, e Ca aumentaram de forma quadrática com as doses de potássio. A aplicação $\mathrm{KCl}$ aumentou respectivamente, de forma quadrática e linear, as exportações de $\mathrm{S}$ e $\mathrm{Cl}$ pelos frutos de melancia.

Palavras-chave: Citrullus lanatus, nutrição de plantas, fertilizantes potássicos.

\begin{abstract}
Nutrients recruitment of watermelon fruits in relation to seasons, potassium sources and doses

Two field experiments were conducted in Borborema, São Paulo State, Brazil, from October to December 2001 and February to April 2002 , to evaluate the nutrients recruitment of watermelon fruits, Tide hybrid, as a result of potassium sources and doses. The experimental design was a randomized complete block, with three replications, in $3 \times 4$ factorial scheme, the sources being evaluated: potassium chloride, nitrate and sulphate and doses of 50; 100; 200 and $300 \mathrm{~kg}$ ha $^{-1} \mathrm{~K}_{2} \mathrm{O}$. Greater recruitment of $\mathrm{N}, \mathrm{P}, \mathrm{K}, \mathrm{Ca}, \mathrm{S}$ and $\mathrm{Cl}$ by watermelon fruits was obtained in the first trial, while the recruitment of $\mathrm{Mg}$ was observed in the second trial. The dry mass and recruitment of $\mathrm{N}, \mathrm{P}$, $\mathrm{K}$, and $\mathrm{Ca}$ increased with potassium doses. $\mathrm{S}$ and $\mathrm{Cl}$ of the watermelon fruits increased with the increase of $\mathrm{KCl}$ doses in a quadratic and linear form, respectively.
\end{abstract}

Keywords: Citrullus lanatus, plant nutrition, potassium fertilizers.

(Recebido para publicação em 17 de fevereiro e 2004 e aceito em 2 de setembro de 2004)

$\mathrm{A}$ produção mundial de melancia em 2002, segundo a FAO (2003), atingiu 89,9 milhões de toneladas e produtividade média de $25,1 \mathrm{t} \mathrm{ha}{ }^{-1}$, tendo o Brasil produzido 620 mil toneladas com produtividade de 7,6 t ha-1. A quantidade de melancia produzida no Brasil ocupa o quarto lugar dentre as olerícolas, que têm produção anual em torno de 12,5 milhões de toneladas. As regiões Sul e Nordeste são as principais produtoras, destacandose os estados do Rio Grande do Sul e Bahia (Chabaribery e Alves, 2001; Camargo Filho e Mazzei, 2002).

No estado de São Paulo, a cultura da melancia ocupou uma área de 7.505 ha, em 2001, com produção de 191.534 toneladas de frutos. Os principais locais de produção são as regiões correspondentes aos Escritórios de Desenvolvimento Rural (EDRs) de Marília (21,0\%), Presidente Prudente (12,0\%), Ourinhos (9,0\%), Tupã $(8,7 \%)$, Assis $(7,6 \%)$, Sorocaba $(6,8 \%)$ e Itapetininga $(5,0 \%)$, totalizando $70 \%$ da produção estadual (IEA, 2002). Essa produção abastece a grande São Paulo, um dos principais centros consumidores, e alguns estados do Sul. No entanto, no período de entressafra a produção vem de outros estados como Goiás, Bahia e Rio Grande do Sul.

A cultura da melancia, a exemplo de outras oleráceas, tem na nutrição mineral um dos fatores que contribui diretamente na produtividade e na qualidade dos frutos. O nitrogênio e o potássio são os nutrientes mais exigidos e devem ser aplicados de forma e quantidade adequadas e na época correta. Tem sido dito que o $\mathrm{N}$ é o nutriente mais importante para aumentar as produções das plantas, porém o K apresenta maior relevância em estabilizá-la, além de exercer efeito na qualidade (Potash and Phosphate Institute of Canada, 1990). Talvez, por essa razão, os estudos com nitrogênio sejam mais numerosos que os envolvendo potássio. Outro fato a ser considerado, é que a maioria dos solos brasileiros apresenta teores médios a altos de $\mathrm{K}$, ocasionando, em geral, pou- ca resposta das culturas às adubações com este nutriente nos primeiros anos de cultivo.

Outro aspecto importante da adubação potássica, pouco explorado na pesquisa, é o estudo comparativo de fontes desse nutriente. Embora o $\mathrm{KCl}$ seja o fertilizante mais utilizado, devido ao seu menor preço e maior disponibilidade no mercado, alguns cuidados devem ser tomados antes de sua utilização, tais como, o elevado índice salino que pode prejudicar a germinação, o sistema radicular e, consequientemente, o desenvolvimento da planta; o aumento do risco de salinização do solo e a possibilidade de haver fitotoxicidade ao cloro. Por isso, fontes como nitrato e sulfato de potássio seriam mais indicadas, pois além de conterem outros nutrientes como $\mathrm{N}$ e $\mathrm{S}$, apresentam menores índices salinos e reduzem os riscos de salinização e efeito deletério às culturas. Entretanto, o maior preço destes fertilizantes tem limitado seu uso na agricultura. 
A cultura da melancia é uma das cucurbitáceas mais exigente em nutrientes e também destaca-se por exportar grandes quantidades dos nutrientes acumulados ao longo do ciclo, através da colheita dos frutos. Grangeiro e Cecílio Filho (2002) verificaram que o híbrido de melancia Tide extraiu no final do ciclo (75 dias após o transplantio) 139; $13 ; 155 ; 25 ; 17 \mathrm{e} 9 \mathrm{~kg} \mathrm{ha}^{-1}$, respectivamente, de N, P, K, Ca, Mg e S. Destes, $77 \%$ do N, $82 \%$ do P, $76 \%$ do K, $17 \%$ do $\mathrm{Ca}, 41 \%$ do $\mathrm{Mg}$ e $65 \%$ do $\mathrm{S}$, foram exportados pelos frutos. Em outro experimento, desta vez com o híbrido de melancia sem sementes Nova, as quantidades exportadas representaram cerca de $38 \%$ do N, $45 \%$ do P, $50 \%$ do K, $11 \%$ do $\mathrm{Ca}, 27 \%$ do $\mathrm{Mg}$ e $33 \%$ do $\mathrm{S}$ do total extraído pela cultura (Grangeiro e Cecílio Filho, 2003). Observa-se, portanto, que o potássio é o nutriente extraído em maior quantidade pela melancieira e juntamente com o $\mathrm{N}$ e $\mathrm{P}$ são os mais exportados pelos frutos.

O presente trabalho teve como objetivo determinar as quantidades exportadas de nutrientes pelos frutos de melancia, em função de fontes e doses de potássio, em duas épocas de cultivo.

\section{MATERIAL E MÉTODOS}

Foram conduzidos dois experimentos em propriedades rurais próximas à cidade de Borborema, de outubro a dezembro de 2001 e de fevereiro a abril de 2002, cujas coordenadas geográficas são $49^{\circ} 5^{\prime}$ 'de longitude, $21^{\circ} 37^{\prime}$ de latitude e $429 \mathrm{~m}$ de altitude. Os solos das áreas experimentais foram classificados como Argissolo Vermelho-Amarelo distrófico textura média. Para a caracterização dos solos foram coletadas amostras compostas na profundidade de 0 a $20 \mathrm{~cm}$ cujas análises químicas revelaram os resultados: área 1 (cultivo de out. a dez. de 2001): $\mathrm{pH}\left(\mathrm{CaCl}_{2}\right)=4,2$; M.O. $=11 \mathrm{~g} \mathrm{dm}^{-3} ; \mathrm{P}$ (resina $)=2 \mathrm{mg} \mathrm{dm}^{-3}$;

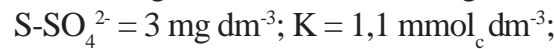
$\mathrm{Ca}=7 \mathrm{mmol}_{\mathrm{c}} \mathrm{dm}^{-3} ; \mathrm{Mg}=3 \mathrm{mmol}_{\mathrm{c}}^{\mathrm{c}} \mathrm{dm}^{-3}$; $\mathrm{H}+\mathrm{Al}=28 \mathrm{mmol}_{\mathrm{cm}}^{-3} ; \mathrm{SB}^{\mathrm{c}}=11$ $\mathrm{mmol}_{\mathrm{c}} \mathrm{dm}^{-3} ; \mathrm{T}=39$ e $\mathrm{V}=28 \%$ e área 2 (cultivo de fev. a abr. de 2002): pH $\left(\mathrm{CaCl}_{2}\right)=4,8$; M.O.= $19 \mathrm{~g} \mathrm{dm}^{-3}$; P (resina) $=3 \mathrm{mg} \mathrm{dm}^{-3} ; \mathrm{SO}_{4}^{2-}=5 \mathrm{mg} \mathrm{dm}^{-3} ; \mathrm{K}=$ $1,0 \mathrm{mmol}_{\mathrm{c}} \mathrm{dm}^{-3} ; \mathrm{Ca}=9 \mathrm{mmol}_{\mathrm{c}} \mathrm{dm}^{-3} ; \mathrm{Mg}$
$=5 \mathrm{mmol} \mathrm{dm}^{-3} ; \mathrm{H}+\mathrm{Al}=16 \mathrm{mmol} \mathrm{dm}^{-3}$; $\mathrm{SB}=15,0 \mathrm{mmol}^{\mathrm{c}} \mathrm{dm}^{-3} ; \mathrm{T}=31 \mathrm{e} \mathrm{V}=48 \%$.

$\mathrm{O}$ delineamento experimental utilizado foi o de blocos casualizados completos, em esquema fatorial $3 \times 4$, com três repetições, sendo avaliadas as fontes cloreto, nitrato e sulfato de potássio e as doses 50; 100; 200 e $300 \mathrm{~kg} \mathrm{ha}^{-1} \mathrm{de}$ $\mathrm{K}_{2} \mathrm{O}$. Cada unidade experimental foi constituída por três linhas de oito plantas, no espaçamento de 3,0 m entrelinhas e 1,7 m entre plantas, e ocupou uma área de $122,4 \mathrm{~m}^{2}$. Utilizou-se a linha central como área útil da parcela, excluindo-se a primeira e última planta da linha.

Após aração e gradagem fez-se a distribuição do calcário dolomítico em área total e a incorporação com grade, 50 dias antes do transplantio e em quantidade para elevar a saturação por bases a 70\% (Raij et al., 1997). Após esse período, procedeu-se a abertura dos sulcos com aproximadamente $30 \mathrm{~cm}$ de profundidade e fez-se a adubação.

$\mathrm{O} \mathrm{N}$ foi aplicado na forma de nitrato de amônio em doses equivalentes a 30 $\mathrm{kg} \mathrm{N} \mathrm{ha-1}$ no sulco de transplantio e 90 $\mathrm{kg} \mathrm{ha}^{-1}$ de $\mathrm{N}$ parcelado em três vezes. Para as doses de 50; 100; 200 e $300 \mathrm{~kg}$ $\mathrm{ha}^{-1}$ de $\mathrm{K}_{2} \mathrm{O}$ fornecidas via nitrato de potássio, foram necessários aplicar 26,3; 22,6; 15,2 e 7,8 $\mathrm{kg} \mathrm{ha}^{-1}$ de nitrato de amônio a fim de complementar a dose de $30 \mathrm{~kg} \mathrm{ha}^{-1}$ de $\mathrm{N}$ prevista para o plantio e em cada uma das três coberturas.

No sulco foram aplicados, também, $240 \mathrm{~kg} \mathrm{ha}^{-1}$ de $\mathrm{P}_{2} \mathrm{O}_{5}$ nas formas de superfosfato simples e de superfosfato triplo, para fornecer $50 \mathrm{~kg} \mathrm{ha}^{-1} \mathrm{de}$ enxofre. Os tratamentos que receberam 200 e $300 \mathrm{~kg} \mathrm{ha}^{-1}$ de $\mathrm{K}_{2} \mathrm{O}$ como $\mathrm{K}_{2} \mathrm{SO}_{4}$, receberam 67 e $100 \mathrm{~kg} \mathrm{ha}^{-1}$ de $\mathrm{S}$, respectivamente.

As doses de $\mathrm{K}$ foram parceladas em $25 \%$ no plantio, $25 \%$ aos 7 dias após o transplantio (DAT), 25\% aos 21 DAT e $25 \%$ aos 35 DAT juntamente com o nitrogênio.

O híbrido utilizado foi Tide, que caracteriza-se pela precocidade, com ciclo médio de 80 a 90 dias do plantio à colheita, e apresenta frutos de formato redondo-ovalado e peso médio de 10 a $12 \mathrm{~kg}$, casca verde-escura com listras verde-claras e polpa vermelho-brilhante. A semeadura foi feita em bandejas de poliestireno expandido para 128 mudas, preenchidas com substrato, nas quais permaneceram em casa de vegetação por um período de 30 dias até o transplantio.

No primeiro experimento, o transplantio foi realizado em 03/10/2001 e no segundo em 14/02/2002, quando as mudas apresentavam duas folhas definitivas. A partir dos 20 DAT, foram feitas adubações foliares semanalmente, junto com os defensivos, empregando $200 \mathrm{ml}$ por $100 \mathrm{~L}$ de solução dos produtos contendo: 0,6 $\mathrm{g} \mathrm{L}^{-1}$ de $\mathrm{Mg} ; 0,8 \mathrm{~g}$ $\mathrm{L}^{-1}$ de Ca e $0,05 \mathrm{~g} \mathrm{~L}^{-1}$ de B; $0,3 \mathrm{~g} \mathrm{~L}^{-1}$ de $\mathrm{Zn} ; 0,2 \mathrm{~g} \mathrm{~L}^{-1}$ de Mn e $0,01 \mathrm{~g} \mathrm{~L}^{-1}$ de Mo. A pluviometria foi de $436 \mathrm{~mm}$ e 253 $\mathrm{mm}$, respectivamente, nos experimentos conduzidos de outubro a dezembro de 2001 e fevereiro a abril de 2002. Não foi realizada irrigação complementar, pois nas áreas experimentais não existiam fontes de captação de água.

Além das pulverizações com defensivos agrícolas, foram realizadas capinas e penteamento das ramas. A colheita dos frutos foi iniciada aos 70 DAT no primeiro experimento e aos 65 DAT no segundo, sendo realizadas respectivamente, três e duas colheitas com intervalos de sete dias.

$\mathrm{Na}$ primeira colheita de cada experimento, selecionou-se dois frutos por parcela e retirou-se uma amostra de aproximadamente 1,0 kg. Em seguida, as mesmas foram colocadas em estufa com circulação forçada de ar a $65^{\circ} \mathrm{C}$, por um período de 96 horas até peso constante. Em função do teor de umidade das amostras, determinou-se a produção de massa seca total dos frutos de cada tratamento. A determinação das concentrações de nutrientes foi feita de acordo com metodologia descrita por Malavolta et al. (1997). No caso do Cl, o método utilizado foi o potenciométrico proposto pela Association of Official Analytical Chemists (AOAC,1970). As quantidades de nutrientes exportadas foram determinadas com base nas concentrações dos nutrientes e na produção de massa seca de frutos.

A análise de variância das variáveis avaliadas foi realizada isoladamente para cada experimento. Depois procedeu-se a análise conjunta dos experimentos com o auxílio do software SAS. Conforme Pimentel Gomes (1990), para 
Tabela 1. Exportação de N, P, K, Ca, Mg, S e Cl pelos frutos de melancia, híbrido Tide, em função da época de cultivo. Mossoró (RN), ESAM, 2001.

\begin{tabular}{lllllllr}
\hline \multicolumn{1}{c}{ Época } & $\mathbf{N}$ & $\mathbf{P}$ & $\mathbf{K}$ & $\mathbf{C a}$ & $\mathbf{M g}$ & $\mathbf{S}$ & $\mathbf{C l}$ \\
\cline { 2 - 8 } & & & & $\mathbf{k g ~ h a}^{-1}$ & & & \\
\hline Out. a dez. de 2001 & $48,5 \mathrm{a}^{1}$ & $3,0 \mathrm{a}$ & $70,6 \mathrm{a}$ & $4,1 \mathrm{a}$ & $4,3 \mathrm{~b}$ & $4,1 \mathrm{a}$ & $4,2 \mathrm{a}$ \\
Fev. a abr. de 2002 & $17,2 \mathrm{~b}$ & $2,0 \mathrm{~b}$ & $59,0 \mathrm{~b}$ & $2,0 \mathrm{~b}$ & $6,8 \mathrm{a}$ & $1,8 \mathrm{~b}$ & $2,7 \mathrm{~b}$ \\
\hline C.V. (\%) & 19,3 & 18,4 & 19,8 & 20,8 & 21,8 & 19,4 & 22,1 \\
\hline
\end{tabular}

${ }^{1}$ Médias seguidas de mesmas letras na coluna, não diferem estatisticamente entre si (Tukey a 5\%).

Tabela 2. Equações de regressão ajustadas para produção de massa seca (MSF), exportação de N, P, K, Ca, S e Cl nos frutos de melancia, híbrido Tide, em função das doses de potássio. Jaboticabal (SP), FCA-UNESP, 2001.

\begin{tabular}{|c|c|c|c|c|}
\hline Característica & Equação de regressão & $\mathbf{R}^{2}$ & Máximo & $\begin{array}{c}\text { Dose máxima } \\
\text { (kg ha-1 de } \mathrm{K} 2 \mathrm{O})\end{array}$ \\
\hline MSF $\left(\mathrm{kg} \mathrm{ha}^{-1}\right)$ & $Y=1108,44+6,21 X-0,02 X^{2}$ & $0,97^{* *}$ & 1.657 & 177 \\
\hline$N\left(\mathrm{~kg} \mathrm{ha}^{-1}\right)$ & $Y=24,03+0,14 X-0,0004 X^{2}$ & $1,00^{* *}$ & 36,7 & 177 \\
\hline $\mathrm{P}\left(\mathrm{kg} \mathrm{ha}^{-1}\right)$ & $Y=1,77+0,01 X-0,00003 X^{2}$ & $0,99^{* *}$ & 2,7 & 174 \\
\hline $\mathrm{K}\left(\mathrm{kg} \mathrm{ha}^{-1}\right)$ & $Y=32,21+0,46 X-0,001 X^{2}$ & $0,99^{* *}$ & 76,8 & 193 \\
\hline \multirow[t]{2}{*}{$\mathrm{Ca}\left(\mathrm{kg} \mathrm{ha}^{-1}\right)$} & $Y=2,26+0,01 X-0,00003 X^{2}$ & $0,95^{* *}$ & 3,3 & 177 \\
\hline & $Y(K C l)=1,53+0,02 X-0,00006 X^{2}$ & $0,92^{* *}$ & 3,5 & 182 \\
\hline \multirow[t]{2}{*}{$\mathrm{S}\left(\mathrm{kg} \mathrm{ha}^{-1}\right)$} & 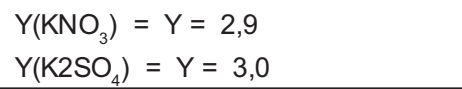 & & & \\
\hline & $Y(\mathrm{KCl})=3,47+0,015 \mathrm{X}$ & $0,85^{\star *}$ & 8,1 & 300 \\
\hline \multirow[t]{2}{*}{$\mathrm{Cl}\left(\mathrm{kg} \mathrm{ha}^{-1}\right)$} & $\mathrm{Y}\left(\mathrm{KNO}_{3}\right)=\mathrm{Y}=2,1$ & & & \\
\hline & $\mathrm{Y}\left(\mathrm{K}^{2} \mathrm{SO}_{4}\right)=2,9-0,003 \mathrm{X}$ & $0,77^{*}$ & 2,7 & 50 \\
\hline
\end{tabular}

*,** significativo ao nível de $1 \%$ e $5 \%$, respectivamente.

o fator quantitativo (doses de K) foi feita análise de regressão, enquanto que para o fator qualitativo (fontes de K) foi utilizado o teste de Tukey, ao nível de $5 \%$ de probabilidade.

\section{RESULTADOS E DISCUSSÃO}

A época de cultivo influenciou as exportações de nutrientes pelos frutos. As exportações de N, P, K e Ca foram também influenciadas pela dose de potássio e as de $\mathrm{S}$ e $\mathrm{Cl}$ pela interação fontes e doses de potássio.

Com exceção do $\mathrm{Mg}$, as maiores exportações de nutrientes pelos frutos no momento da colheita foram obtidas no cultivo de outubro a dezembro de 2001 (Tabela 1). A maior precipitação pluviométrica neste período proporcionou maior absorção de nutrientes e, consequentemente, redistribuição para os frutos.

A massa seca de frutos aumentou em função das doses de potássio, atingindo o máximo de $1.657 \mathrm{~kg} \mathrm{ha}^{-1}$ na dose de $177 \mathrm{~kg} \mathrm{ha}^{-1}$ de $\mathrm{K}_{2} \mathrm{O}$ (Tabela 2). As exportações de N, P, K e Ca em função das doses de potássio, aumentaram de forma quadrática, atingido-se pontos máximos nas doses $177 \mathrm{~kg} \mathrm{ha}^{-1}$ de $\mathrm{K}_{2} \mathrm{O}$ para $\mathrm{Ne} \mathrm{Ca}, 174 \mathrm{~kg} \mathrm{ha}^{-1}$ de $\mathrm{K}_{2} \mathrm{O}$ para $\mathrm{P}$ e $193 \mathrm{~kg} \mathrm{ha}^{-1}$ de $\mathrm{K}_{2} \mathrm{O}$ para K (Tabela 2). O aumento na produção de massa seca de frutos, proporcionado pela adubação potássica, favoreceu também a maior exportação de nutrientes. Na batateira, embora não tenha havido acréscimo na produção de massa seca dos tubérculos em função da adubação potássica, na forma de $\mathrm{K}_{2} \mathrm{SO}_{4}$, as exportações de $\mathrm{K}$, $\mathrm{Ca}, \mathrm{Mg}, \mathrm{S}$ e Cl aumentaram (Reis Júnior e Monnerat, 2001). Em tomateiro, à medida que se aumentou a concentração de K na solução nutritiva, a concentração de $\mathrm{K}$ na folha e fruto, bem como as quantidades extraídas pelos mesmos aumentaram (Montoya et al., 2002).

Uma das funções do potássio na planta, é intensificar o armazenamento de solutos do floema em órgãos como sementes, tubérculos e frutos, tendo sido demonstrado que a velocidade de transporte aumenta com um alto suprimento de potássio (Potash and Phosphate Institute of Canada, 1990). Na cultura da melancia, é o nutriente extraído em maior quantidade, com maior demanda após a frutificação (Grangeiro e Cecílio Filho, 2002; 2003), quando ocorre uma intensificação da translocação de fotossintatos, principalmente, em favor dos frutos. Nessa fase, também são verificadas as maiores extrações de nutrientes.

O desdobramento da interação, doses dentro de cada fonte de potássio, para a exportação de $\mathrm{S}$ nos frutos, revelou efeito significativo apenas para o $\mathrm{KCl}$. Nessa fonte, o aumento na dose proporcionou aumento na exportação de $\mathrm{S}$ de forma quadrática, com máximo $(3,5 \mathrm{~kg}$ $\mathrm{ha}^{-1}$ ) alcançado na dose de $182 \mathrm{~kg} \mathrm{ha}^{-1}$ de $\mathrm{K}_{2} \mathrm{O}$. As quantidades médias de $\mathrm{S}$, exportadas nas fontes $\mathrm{KNO}_{3}$ e $\mathrm{K}_{2} \mathrm{SO}_{4}$ foram, respectivamente, de 2,9 e $3,0 \mathrm{~kg}$ ha $^{-1}$ (Tabela 2). A exportação de $\mathrm{Cl}$ pelos frutos, na adubação efetuada com $\mathrm{KCl}$ foi linear, atingindo $8,1 \mathrm{~kg} \mathrm{ha}^{-1} \mathrm{na}$ dose $300 \mathrm{~kg} \mathrm{ha}^{-1}$ de $\mathrm{K}_{2} \mathrm{O}$. Segundo Nogueira et al. (2001), plantas que recebem doses de $\mathrm{KCl}$ como fonte de $\mathrm{K}$, podem apresentar quantidades elevadas de $\mathrm{Cl}$ por kg de massa seca, no entanto, isso não deve refletir sua necessidade nutricional. Na cultura do pimentão, Silva (1998) obteve acúmulo de 4.400 
$\mathrm{mg} \mathrm{kg}{ }^{-1}$ de $\mathrm{Cl}$ no fruto, quando aplicou $16,6 \mathrm{~g} \mathrm{~m}^{2} \mathrm{de} \mathrm{KCl}$. Todavia, as altas quantidades de $\mathrm{Cl}$ absorvidas pelo pimentão não causaram sintomas de toxicidade visíveis nas folhas, embora a produção tenha diminuído.

Com a aplicação de $\mathrm{K}_{2} \mathrm{SO}_{4}$, o comportamento foi inverso, ou seja, à medida que se aumentou a dose desse fertilizante, houve uma redução da quantidade exportada de $\mathrm{Cl}$ nos frutos (Tabela 2). Provavelmente, a inibição competitiva entre os ânions $\mathrm{SO}_{4}{ }^{2-} \mathrm{e} \mathrm{Cl}^{-}$ (Malavolta et al., 1997), tenha limitado a absorção deste último, e consequentemente, seu acúmulo no fruto. Na fonte $\mathrm{KNO}_{3}$, não houve diferença significativa entre as doses de potássio na exportação de $\mathrm{Cl}$ pelo fruto, sendo obtido uma exportação média de 2,1 $\mathrm{kg} \mathrm{ha}^{-1}$ (Tabela 2).

De uma forma geral, as quantidades de nutrientes exportadas pelos frutos em ambos experimentos (Tabela 1) foi inferior aos obtidos por Grangeiro e Cecílio Filho (2002) quando trabalharam com o mesmo híbrido (Tide). Por outro lado, foram superiores aqueles valores obtidos, para o híbrido de melancia sem sementes Nova, em trabalho realizado por Grangeiro e Cecílio Filho (2003) no estado de São Paulo. Segundo Marschner (1995) as quantidades de nutrientes extraídas e exportadas pelas plan- tas, dependem de uma série de fatores, tais como espécies e cultivares, clima, interação e mobilidade dos nutrientes no solo e na planta, entre outros.

\section{AGRADECIMENTOS}

À FAPESP por auxílio financeiro concedido para a realização deste trabalho.

\section{LITERATURA CITADA}

ANUÁRIO DE INFORMAÇÕES ESTATATÍSTICA DA AGRICULTURA: Anuário IEA, 2001. São Paulo: IEA, 2002. 245 p. ASSOCIATION OF OFFICIAL ANALYTICAL CHEMISTRY. Official methods of analysis of the Association of official Analytical Chemists. 11ed. Washington, 1970, $1015 \mathrm{p}$.

CAMARGO FILHO, W.P.; MAZZEI, A.R. O mercado de melancia no mercosul. Informações Econômicas, São Paulo, v.32, n.2, p.61-64, 2002. CHABARIBERY, D.; ALVES, H.S. Produção e comercialização de limão, mamão, maracujá e melancia em São Paulo. Informações Econômicas, São Paulo, v.31, n.8, p.43-51, 2001.

FAO (Roma, Italy). Agricultural production, primary crops. Disponível em <http:// www.fao.org>. Acesso em 29 jan. 2003.

GRANGEIRO, L.C.; CECÍLIO FILHO, A.B Marcha de absorção de nutrientes pela cultura da melancia. In: REUNIÃO BRASILEIRA DE FERTILIDADE DO SOLO E NUTRIÇÃO DE PLANTAS 25., REUNIÃO BRASILEIRA SOBRE MICORRIZAS 9., SIMPÓSIO BRASILEIRO DE MICROBIOLOGIA DO SOLO 7., REUNIÃO BRASILEIRA DE BIOLOGIA DO SOLO 4., 2002, Rio de Janeiro. Anais... 1 CD- ROM.
GRANGEIRO, L.C.; CECÍLIO FILHO, A.B. Acúmulo e exportação de macronutrientes pela melancia sem sementes, híbrido Nova. Horticultura Brasileira, Brasília, DF, v.21, n.2. Suplemento 2. CD-ROM. Trabalho apresentado no $43^{\circ}$ Congresso Brasileiro de Olericultura, 2003.

MALAVOLTA, E.; VITTI, G.C.; OLIVEIRA, S.A. Avaliação do estado nutricional das plantas: princípios e aplicações. Piracicaba: POTAFOS, 1997. $201 \mathrm{p}$.

MARSCHNER, H. Mineral nutrition of higher plants. San Diego: Academic Press, 1995. 889 p. MONTOYA, R.B.; SPINOIA, A.G.; GARCIA, P.S.; PAREDES, D.G. Demanda de potasio del tomate tipo saladette. Disponível em: <http:// www.chapingo.mx/terra/contenido/20/4art391399.pdf.>. Acesso em: 18 dez. 2002.

NOGUEIRA, F.D.; SILVA, E.B.; GIMARÃES, P.T.G. Adubação potássica do cafeeiro: sulfato de potássio. Washington, DC: SOPIB, 2001. $81 \mathrm{p}$. PIMENTEL GOMES, F. Curso de estatística experimental. 12 ed. Piracicaba: Nobel, 1990, 466 $\mathrm{p}$.

POTASH \& PHOSPHATE INSTITUTE OF CANADA. Potássio: necessidade e uso na agricultura moderna. Piracicaba, POTAFOS, 1990. 45 p.

RAIJ, B.; CANTARELLA, H.; QUAGGIO, J.A.; FURLANI, A.M.C. Recomendações de adubação e calagem para o estado de São Paulo. Campinas, 1997. 285p. (Boletim Técnico, 100).

REIS JÚNIOR, R.A.; MONNERAT, P.H. Exportação de nutrientes nos tubérculos de batata em função de doses de sulfato de potássio. Horticultura Brasileira, Brasília, v.19, n.3, p.360364, 2001.

SILVA, M.A.G. Efeito do nitrogênio e potássio na produção e nutrição do pimentão em ambiente protegido. 1998. 86f. (Tese doutorado) ESALQ, USP, Piracicacaba, 1998. 